\title{
Road traffic injuries and risk factors
}

\author{
Abdulbari Bener ${ }^{1,2,3}$, Huseyin R. Burgut ${ }^{1}$,Heba Sidahmed ${ }^{1}$, Rama AlBuz, Rahima Sanya ${ }^{1}$, \\ Waleed Ali Khan ${ }^{1}$ \\ ${ }^{1}$ Depts. of Public Health \& Medical Education, Weill Cornell Medical College, Qatar \\ ${ }^{2}$ Dept. of Medical Statistics \& Epidemiology, Hamad Medical Corporation, Weill Cornell \\ Medical College, Hamad General Hospital, Qatar \\ ${ }^{3}$ Dept. Evidence for Population Health Unit, School of Epidemiology and Health Sciences, \\ The University of Manchester, Manchester, UK
}

\begin{abstract}
This study determines the characteristics of Road Traffic Injuries (RTIs) among Qatari drivers and examines the human behavioural and environmental risk factors associated in occurrence of RTIs. This cross sectional survey was conducted in the primary health care centers during the period of February July 2009. A random sample of 1800 Qatari drivers was approached and 1406 drivers responded and agreed to participate in this study (78.1\%). Face to face interview was conducted by well trained research assistants based on a questionnaire. The study revealed that of the studied Qatari drivers (1406), 14.5\% of them were injured. Young drivers in the age group $(25$ - 34) years were more involved in RTIs (35.8\%). The RTIs occurred more among male drivers than females with the ratio 1.7:1 $(\mathrm{p}<0.001)$. Of the injured drivers, 63.7\% were involved with traffic violations especially with exceeding speed limit (25.9\%) and parking violation (18.1\%). Qatari drivers were more injured from overturn skid crashes (20.6\%) and hitting fixed objects (14.7\%). Head injuries were reported more from light vehicle crashes (33.3\%) and neck injuries from Pickup and SUVs crashes (44.7\%). Severe injuries were reported among Qatari drivers who had heavy vehicle crashes (43.5\%). The study findings revealed the high risk of RTIs was among young male Qatari drivers in the age group 25-34 years. It showed that human behavioural factors represent one of the main causes of RTIs such as excessive speed and using seatbelt.
\end{abstract}

(C) 2009 Californian Journal of Health Promotion. All rights reserved.

Keywords: Road Traffic Injuries, driver behavior, excessive speed, traffic violations, Qatar

\section{Introduction}

Motorization has enhanced the lives of many individuals and societies, but the benefits have come with a high price. Road Traffic Injury (RTI), one of the most common injuries, is defined as a fatal or non-fatal injury incurred as the result of a road traffic crash. RTIs are thought to be the most common cause of death, resulting in 1.26 million each year, $20.7 \%$ of all deaths from injuries (Krug, 2004). In addition to these deaths, between 20 and 50 million people globally are estimated to be injured or disabled each year (Peden, 2005) Current and projected trends in motorization indicate that the problem of RTIs will get worse, leading to a global public health crisis (World Health Organization, 2004). RTIs have been reported to be the tenth leading cause of death and the ninth leading contributor to the burden of disease worldwide (Peden et al., 2004). By 2020, RTIs will become the third leading contributor to the global burden of disease and injuries.

Injuries resulting from RTIs disproportionately affect vulnerable road users in developing countries. Developed countries such as U.K and U.S.A (Jacob, Aeron-Thomas \& Astrop, 2000) 
A. Bener, H. R. Burgut ,H. Sidahmed, R. AlBuz, R. Sanya, W. A. Khan / Californian Journal of Health Promotion 2009, Volume 7,

have taken the issue of road traffic crashes very seriously, initiating certain policies and actions for its improvement. These programs and polices have now stabilized and reduced fatalities in these countries. But, other countries including the Asian, African and the Middle East have not been able to either stabilize or reduce the fatalities. The problem is increasing at a fast rate in developing countries due to rapid motorization and other factors.

The state of Qatar has witnessed progressive development in infrastructure and economy during the last decade. However, the dramatic growth of urban population caused a rapid rise in urban vehicle ownership and accidents. The State of Qatar in a short time has played a leading role in industrialization and in cultural activities. The process of rapid urbanization and huge growth of vehicles and population have resulted alarming increase in the number of road traffic crashes and morbidity and mortality owing to RTIs. A previous study (Bener, 2009a) of Qatar reported that since 1993 there was a sharp increase in number of registered vehicles by $194 \%$ in 2007 and road traffic accidents (147\%). Also, there was an increase of $71.8 \%$ in number of injuries, whereas a higher increase was observed in fatalities (135\%).

RTIs are modulated by human behavioural and environmental factors. Many studies (Bener et al., 2008a; Bener, Lajunen, Ozkan \& Haigney, 2006; Bener, Ozkan \& Lajunen, 2008b; Bener \& Crundall, 2008c; Bener et al., 2007) have shown that human behavioural factors collectively represent the main cause of road traffic crashes and their remedial measures can go a long way to help prevent RTIs. Sabbagh Ebrlich et al reported that the postulated risk factors include driver fatigue and other forms of risky driving behaviours, overcrowding of vehicles, poor condition of vehicles and poor road networks (Sabbagh Ebrlich, Friedman \& Richter, 2005).

In Qatar, without appropriate action, RTIs are predicted to escalate in the future. Hence, it is important to conduct a cross sectional survey to study the determinants of the RTIs. In this article, we provide an overview of the characteristics of injuries sustained following road traffic crashes and examine the human behavioural and environmental risk factors.

\section{Subjects and Methods}

This is a cross-sectional study, carried out at the Primary Health Care (PHCs) Center by using their registry. The survey was conducted from January 2009 to June 2009, among Qatari drivers. Following informed consent, each participant was interviewed by a pre-trained interviewer using a standard questionnaire covering socio-demographic information, driving history, type of vehicle, severity and type of injuries, nature of injuries and behavioural factors of injured drivers. The sample size was determined on a prior presumption that the prevalence rate of RTIs in UAE (Bener et al., 2006) and in Qatar (Bener et al., 2007) is around $12 \%$ would be more or less similar to rates found for several other countries in the Arabian Gulf. Assuming the prevalence of RTIs to be $12 \%$, with the $95 \%$ confidence interval for an error of $1.5 \%$ at the level of significance, a sample size of about 1,800 would be required to meet the specific objectives of the study.

Out of 22 primary health care centers, 9 health centers were located in urban and 3 in semiurban areas of Qatar. The study included all Qatari men and women aged 18 years and above who attended these PHC centers and were willing to participate in the study. During the study period, 1,800 subjects were approached, of whom 1,406 responded to the questionnaire, for a response rate of 78.1\%. Non-Qataris, pregnant women, subjects with severe medical condition or mental disorder, those who did not meet the eligibility criteria or those who were not willing to participate in the study, were excluded from the analysis. A letter of consent was provided to the participants before the interview along with explanation of the study. IRB exemption for the study was obtained from Weill Cornell Medical College in New York.

Student-t test was used to ascertain the significance of differences between mean values of two continuous variables and confirmed by non-parametric Mann-Whitney test. Fisher exact 
A. Bener, H. R. Burgut ,H. Sidahmed , R. AlBuz, R. Sanya, W. A. Khan / Californian Journal of Health Promotion 2009, Volume 7, Issue 2, 92-101

and Chi-square tests were performed to test for differences in proportions of categorical variables between two or more groups. The level $\mathrm{p}<0.05$ was considered as the cut-off value for significance.

Table 1. Socio-demographic characteristics of the studied Qatari drivers according to the history of road traffic injuries $(\mathrm{N}=1406)$

\begin{tabular}{|c|c|c|c|}
\hline Variables & $\begin{array}{c}\text { RTI } \\
\mathrm{N}=204 \\
\mathrm{n}(\%)\end{array}$ & $\begin{array}{c}\text { No RTI } \\
\text { N=1202 } \\
n(\%)\end{array}$ & P Value \\
\hline \multicolumn{4}{|l|}{ Age group } \\
\hline $18-24$ & 18(8.8) & $180(15.0)$ & \\
\hline $25-34$ & $73(35.8)$ & $389(32.4)$ & \\
\hline $35-44$ & $54(26.5)$ & $309(25.7)$ & 0.093 \\
\hline $45-54$ & $45(22.1)$ & 215(17.9) & \\
\hline$>=55$ & 14(6.9) & 109(9.1) & \\
\hline \multicolumn{4}{|l|}{ Gender } \\
\hline Male & $128(62.7)$ & $898(74.7)$ & $<0.001$ \\
\hline Female & $76(37.3)$ & $304(25.3)$ & \\
\hline \multicolumn{4}{|l|}{ Marital Status } \\
\hline Single & $53(26.0)$ & 383(31.9) & 0.093 \\
\hline Married & 151(74.0) & $819(68.1)$ & \\
\hline \multicolumn{4}{|c|}{ Household income per month (QRs) } \\
\hline$<.5000$ & 14(6.9) & $114(9.5)$ & \\
\hline $5000-9999$ & $56(27.5)$ & $442(36.8)$ & 0.017 \\
\hline 10000-14999 & $58(28.4)$ & 271(22.5) & \\
\hline$>15000$ & $76(37.3)$ & $375(31.2)$ & \\
\hline \multicolumn{4}{|l|}{ Education level } \\
\hline Illiterate & $8(3.9)$ & $64(5.3)$ & \\
\hline Primary & $24(11.8)$ & $148(12.3)$ & \\
\hline Intermediate & 68(33.3) & 212(17.6) & $<0.001$ \\
\hline Secondary & $63(30.9)$ & 371(30.9) & \\
\hline University & $41(20.1)$ & 407(33.9) & \\
\hline \multicolumn{4}{|l|}{ Driving experience } \\
\hline$<1$ Year & $16(7.8)$ & $87(7.2)$ & \\
\hline $1-3$ years & $54(26.5)$ & $365(30.4)$ & 0.413 \\
\hline $3-5$ years & $50(24.5)$ & 239(19.9) & \\
\hline$>5$ years & $84(41.2)$ & $511(42.5)$ & \\
\hline \multicolumn{4}{|l|}{ Are you an Owner of Vehicle } \\
\hline Yes & $150(73.5)$ & $899(74.8)$ & 0.702 \\
\hline No & $54(26.5)$ & $303(25.2)$ & \\
\hline
\end{tabular}


A. Bener, H. R. Burgut ,H. Sidahmed, R. AlBuz, R. Sanya, W. A. Khan / Californian Journal of Health Promotion 2009, Volume 7, Issue 2, 92-101

\section{Results}

Table 1 reveals the socio-demographic characteristics of the studied Qatari drivers according to the history of RTIs. Of the studied Qatari drivers (1406), 14.5\% of them were injured. The highest number of injured Qatari drivers was in the age group $(25-34)$ years (35.8\%). Males were more commonly involved with RTIs than females, with the ratio 1.7:1. A significant difference was observed in terms of gender $(p<0.001)$. The Qatari drivers with more than five years of driving experience were more involved with RTIs (41.2\%). Also, drivers with high household income per month (>QRs.15000) were more involved with RTIs $(37.3 \%)(p=0.017)$.

Table 2. Evaluation of human behavioral risk factors of the studied drivers according to the history of road traffic injuries $(\mathrm{N}=1406)$

\begin{tabular}{l|c|c|c}
\hline \hline \multicolumn{1}{c|}{ Variables } & $\begin{array}{c}\text { RTI } \\
\text { N=204 } \\
\mathrm{n}(\%)\end{array}$ & $\begin{array}{c}\text { No RTI } \\
\mathrm{N}=1202 \\
\mathrm{n}(\%)\end{array}$ & P Value \\
\hline \hline Do you use seat belt while driving? & & & \\
\hline Always & $156(76.5)$ & $966(80.4)$ & \\
\hline Sometimes/never & $48(23.5)$ & $236(19.6)$ & 0.200 \\
\hline Distraction habits while driving* & & & \\
\hline Smoking & $17(8.3)$ & $188(15.6)$ & 0.006 \\
\hline Eating or drinking & $58(28.4)$ & $410(34.1)$ & 0.112 \\
\hline Use Mobile Phone & $51(25)$ & $530(44.1)$ & \\
\hline SMS/Text & $48(23.5)$ & $247(20.5)$ & 0.334 \\
\hline Do you follow traffic speed limit & & & \\
\hline Always & $148(72.5)$ & $890(74)$ & \\
\hline If radar/camera installed (sometimes) & $46(22.5)$ & $252(21)$ & 0.877 \\
\hline Never & $10(4.9)$ & $60(5)$ & \\
\hline Violations & & & \\
\hline Red Light Violation & $28(13.7)$ & $148(12.3)$ & 0.573 \\
\hline Exceeding Speed Limit & $53(25.9)$ & $232(19.3)$ & 0.035 \\
\hline Stop or Yield violation & $12(5.9)$ & $64(5.3)$ & 0.745 \\
\hline Parking Violation & $37(18.1)$ & $115(9.6)$ & $<0.001$ \\
\hline \hline
\end{tabular}

Table 2 evaluates human behavioral risk factors of the studied Qatari drivers according to the history of RTIs. Majority of the injured drivers were using seat belt while driving $(76.5 \%)$ and followed the traffic speed limit (72.5\%). 28.4\% of the injured Qatari drivers were distracted with eating or drinking (28.4\%), followed by using mobile phone (25\%). The most common traffic violations of the injured drivers were exceeding speed limit (25.9\%) and parking violation (18.1\%). There was a significant difference found in terms of exceeding speed limits $(p=0.035)$ and parking violation $(p<0.001)$ between both the injured and non-injured groups.

Table 3 shows the environmental risk factors associated in occurrence of RTIs. Most of the RTIs occurred during the hot climate (79.9\%) and sunny day (88.7\%). Also, road traffic crashes at the roundabout led to higher injuries (57.8\%). 
A. Bener, H. R. Burgut ,H. Sidahmed, R. AlBuz, R. Sanya, W. A. Khan / Californian Journal of Health Promotion 2009, Volume 7,

Table 3. Evaluation of environmental risk factors associated in occurrence of Road traffic injuries $(\mathrm{N}=\mathbf{2 0 4})$

\begin{tabular}{|c|c|}
\hline Variables & Frequency (\%) \\
\hline \multicolumn{2}{|l|}{ Weather - Temperature } \\
\hline Hot & 163(79.9) \\
\hline Moderate & $41(20.1)$ \\
\hline \multicolumn{2}{|l|}{ Weather- Sky } \\
\hline Dusty & 14(6.9) \\
\hline Sunny & 181(88.7) \\
\hline Rainy & $9(4.4)$ \\
\hline \multicolumn{2}{|l|}{ Accident Location } \\
\hline Main Road & $15(7.4)$ \\
\hline Side Road & $19(9.3)$ \\
\hline At the crossroad & $15(7.4)$ \\
\hline Roundabout & $118(57.8)$ \\
\hline Traffic Light & 14(6.9) \\
\hline Alley & 23(11.3) \\
\hline
\end{tabular}

Table 4 shows the distribution of RTIs among victims according to mode of transport. Higher occurrence of injuries was from Pickup and SUVs crashes (37.3\%). The highest number of victims who were injured from light vehicle (43.9\%) and Pickup and Sports utility vehicles (SUVs) (47.4\%) were in the age group 25-34 years, whereas from heavy vehicle in the age group 45-54 years (30.6\%). Head injury (33.3\%) was more common with light vehicle crashes. Neck injuries were more common with Pickup and SUVs (44.7\%). Most of the injured drivers were hospitalized (97\%) for their injuries.

Figure 1shows the distribution of nature of injuries resulting from road traffic crashes. The highest occurrence of RTIs was from overturn skid (20.6\%), followed by hitting fixed object (14.7\%) and nose to tail (11.8\%).

\section{Discussion}

RTIs are responsible for a substantial fraction of morbidity and mortality and responsible for more years of life lost than most of human diseases. The injury profile for road traffic crashes in developing countries differs in important ways from the profile seen in developed countries, and it can provide guidance for making policies to improve prevention and control. Hence, the present study was conducted to investigate the determinants of the RTIs among the Qatari drivers with an aim to highlight the importance of road safety and injury prevention. The study has also demonstrated how RTIs were caused, type of injuries by mode of transport and outcome in these vulnerable road users.

The distribution of RTIs varies dramatically 
A. Bener, H. R. Burgut ,H. Sidahmed , R. AlBuz, R. Sanya, W. A. Khan / Californian Journal of Health Promotion 2009, Volume 7, Issue 2, 92-101

Table 4. Distribution of Road Traffic injuries among victims according to mode of transport $(\mathrm{N}=\mathbf{2 0 4})$

\begin{tabular}{|c|c|c|c|c|}
\hline \multirow[b]{2}{*}{ Variables } & \multicolumn{3}{|c|}{ Road Traffic Injuries (N=204) } & \multirow[b]{2}{*}{ P Value } \\
\hline & $\begin{array}{l}\text { Heavy vehicle } \\
\qquad \begin{array}{c}\mathrm{N}=62 \\
\mathrm{n}(\%)\end{array}\end{array}$ & $\begin{array}{c}\text { Light vehicle } \\
\mathrm{N}=66 \\
\mathrm{n}(\%)\end{array}$ & $\begin{array}{c}\text { Pickup and } \\
\text { SUVs } \\
\text { N=76 } \\
\mathrm{n}(\%)\end{array}$ & \\
\hline \multicolumn{5}{|l|}{ Age group } \\
\hline $18-24$ & $11(17.7)$ & $4(6.1)$ & $3(3.9)$ & \\
\hline $25-34$ & $8(12.9)$ & 29(43.9) & $36(47.4)$ & \\
\hline $35-44$ & $13(21)$ & $20(30.3)$ & $21(27.6)$ & $<0.001$ \\
\hline $45-54$ & 19(30.6) & 13(19.7) & $13(17.1)$ & \\
\hline$>=55$ & 11(17.7) & $0(0)$ & $3(3.9)$ & \\
\hline \multicolumn{5}{|l|}{ Severity of Injury } \\
\hline Minor & $0(0)$ & $3(4.5)$ & $1(1.3)$ & \\
\hline Moderate & $35(56.5)$ & $47(71.2)$ & $63(82.9)$ & - \\
\hline Severe & $27(43.5)$ & $16(24.2)$ & $12(15.8)$ & \\
\hline \multicolumn{5}{|l|}{ Type of Injury } \\
\hline Head & $3(4.8)$ & $22(33.3)$ & $15(19.7)$ & \\
\hline Neck & 21(33.9) & $20(30.3)$ & $34(44.7)$ & \\
\hline Back & $24(38.7)$ & $0(0)$ & $9(11.8)$ & \\
\hline Arm & $2(3.2)$ & $0(0)$ & $2(2.6)$ & - \\
\hline Leg & $8(12.9)$ & $6(9.1)$ & $4(5.3)$ & \\
\hline Chest & $4(6.5)$ & $12(18.2)$ & $6(7.9)$ & \\
\hline Abdomen & $0(0)$ & $6(9.1)$ & $6(7.9)$ & \\
\hline Others & $0(0)$ & $0(0)$ & $0(0)$ & \\
\hline \multicolumn{5}{|l|}{ Outcome of Injury } \\
\hline Minor cases (Went home) & $0(0)$ & $3(4.5)$ & $3(3.9)$ & \\
\hline Hospitalized & $62(100)$ & 63(95.5) & 73(96.1) & - \\
\hline
\end{tabular}

* Sports Utility Vehicle

across countries or world regions, not only in terms of age or sex groupings, but also in terms of road user groups and risk factors like human behaviours (Paulozzi, Rayan,, EspitiaHardeman, \& Xi. (2007). In the study sample, the prevalence of RTIs was $14.5 \%$ and it particularly affected the productive (working) age group (25 - 34) years (35.8\%). In India, the highest number victims were between 20 and 29 years of age (29.4\%) (Patil, Kakade, Durgawale \& Kakade, 2008). A national study done in Malaysia (Ministry of Public Health Malaysia, 1997) reported that majority of RTIs occurred among 10 to 19 years, followed by $20-29$ years. Higher occurrence of RTIs among adults is well documented in other studies (Peden, McGee \& Sharma, 2002; Twisk \& Stacey, 2007). This shows that the economic impact of
RTIs is especially damaging because economically active age group are the most vulnerable to such injuries. Our data shows that the proportion of victims was low in the age group (18-24) years (8.8\%) and above the age of 55 years $(6.9 \%)$, which is similar to the findings reported by Jha et al (2003).

The present study investigated the factors strongly associated with the risk of motor vehicle occupant injury, age, gender, environmental issues and human behaviour. The predominance of males in road injury was common in the present study with the ratio 1.7:1. But in India (Patil, Kakade, Durgawale \& Kakade, 2008), a higher ratio was observed in male drivers (4.6:1). The over presentation of males is probably related to their higher 
exposure to road traffic due to economic opportunities and also higher risk taking behaviour. Nantulya and Reich (2003) reported that the more involvement of men in RTIs is a common finding globally.

Figure 1: Distribution of nature of injuries resulting from Road traffic crashes.

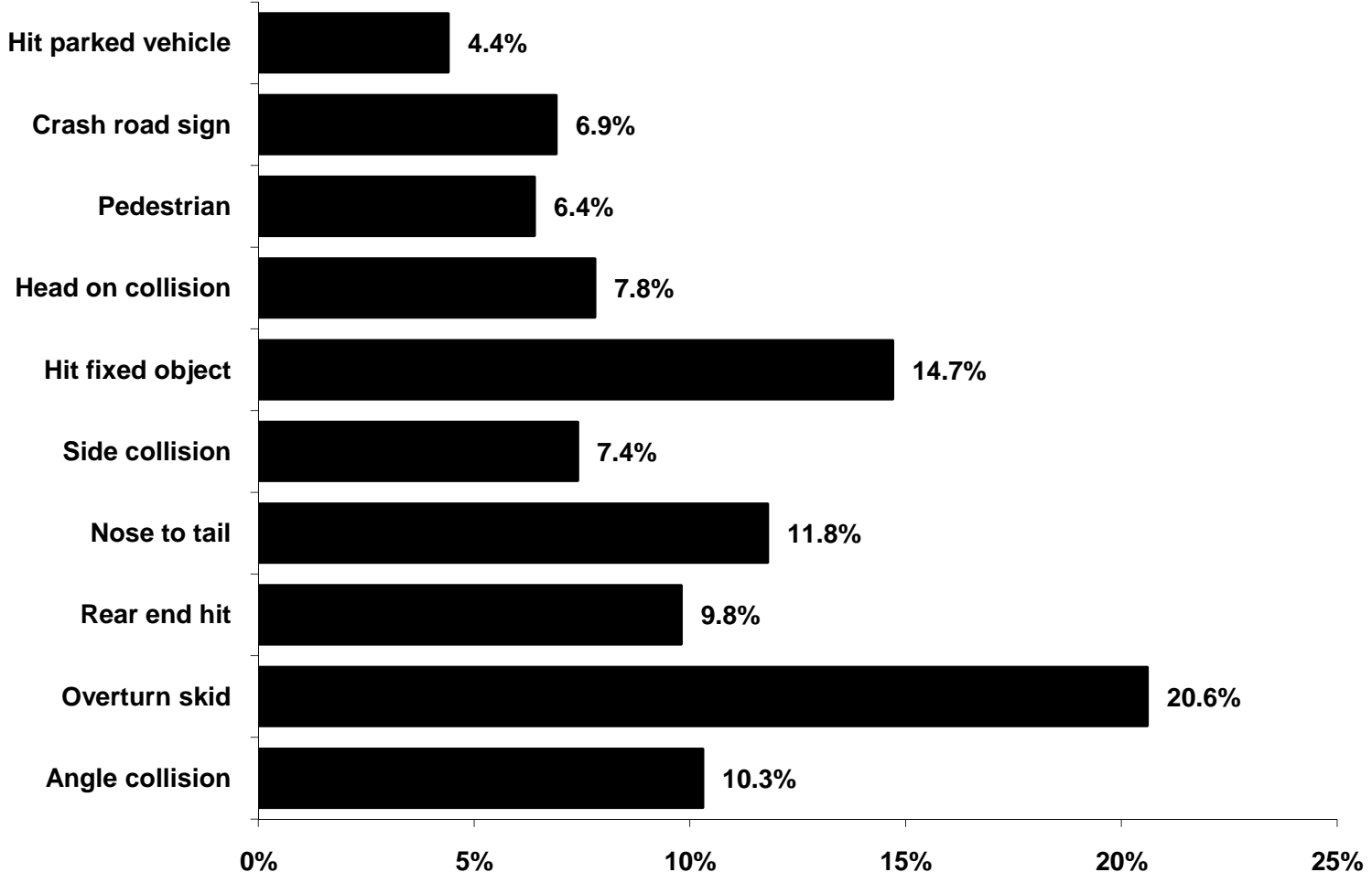

Evidence of high driving speed and driver negligence was examined in some studies especially excessive speed as the main cause of crashes and injuries (Hirst, Mountain \& Maher, 2005; Wong, Sze, Lo, Hung \& Loo, 2005; Finch, Kompfner, Lockwood, \& Maycock, 1994). Despite the fact that majority of the injured Qatari drivers obeyed the traffic rules like using seat belts (76.5\%) and following traffic speed limit $(72.5 \%)$, more than half of them (63.7\%) were involved with traffic violations. Although no significant difference was observed between the injured (72.5\%) and non-injured drivers (74\%) in their response that they were following the traffic rules on speed limit, exceeding speed limit was significantly more common among the injured drivers (25.9\%; $\mathrm{p}=0.035)$. The possible explanation for this finding is that the injured drivers might not observe the traffic speed limit while they were driving. It has been shown that an increase of
$1 \mathrm{~km} / \mathrm{h}$ in mean traffic speed results in a $3 \%$ increase in the incidence of injury crashes and a 4-5\% increase in the fatal crashes22. Eating and drinking (28.4\%) and using mobile phones (25\%) were the most common distraction habits reported among the study group of injured drivers. These study findings reveal that human behavioural factors represent one of the main causes of RTIs.

The data showed that RTIs are also related to vehicle and environmental issues. Most of the RTIs occurred during the hot climate $(79.9 \%)$ and sunny day (88.7\%). For the road safety planners, the study findings highlighted the types of road traffic crashes resulting to more number of injuries were from overturn skid (20.6\%), hitting fixed objects (14.7\%), nose to tail (11.8\%) and angle collision (10.3\%). These causes of road injuries can be attributed to factors as rapid urbanization and motorization, 
which results in increased exposure levels to environmental risk factors of RTIs.

There was an association between mode of transport and the severity of road traffic injury. In the study sample, injuries from heavy vehicle crashes gave largest proportion of severe injuries (43.5\%). Head injuries were reported more from light vehicle crashes (33.3\%), whereas neck injuries from Pickup and SUVs crashes (44.7\%). A previous study done in Qatar (Bener, Abdul Rahman \& Mitra, 2009b) revealed that the maximum number of road traffic crashes victims for head and neck injury was found between the age group $(20-44)$ years (68.5\%). Gururaj (2002) stated that head injuries are reported to be the main cause of mortality in motor traffic vehicle users. The reasons for these injuries could be due to the improper or lack of use of seat belts. Seat belt effectively reduces serious injuries. To improve the human behaviour, driver education programmes can increase knowledge, but this rarely results in appropriate behaviour change. The explanation for the high burden for RTIs is poor enforcement of traffic safety regulations due to administrative policies and lack of effective traffic awareness programs.

\section{Conclusion}

In general, young male drivers were involved in more collisions and have higher RTIs because of their risk taking behaviour while driving. Higher occurrence of RTIs was among adults 25-34 years. The male drivers were more at risk than females of being injured in crashes. It showed that human behavioural factors represent one of the main causes of RTIs. The causes of RTIs have been reported as excessive speed, failure to use protective measures like seatbelts. Head and neck injuries were reported more among drivers. Severe injuries were more prevalent among heavy vehicle crashes. Prevention and control with emphasis on behavioural changes, education and law enforcement may reduce the number of RTIs from crashes in the future.

\section{Acknowledgements}

This work was generously supported and funded by the Qatar National Research Fund- QNRF UREP 05-103-3-026. The authors would like to thank the Weill Cornell Medical College for their support and ethical approval.

\section{References}

Bener, A., Abdul Rahman, Y. S., \& Mitra, B. (2009b). Incidence and severity of head and neck injuries in victims of road traffic crashes: In an economically developed country. International Emergency Nursing, 17, 52-59.

Bener, A., Al-Maadid, M., Ozkan, T., Al-Bast, D. A. E., Diyab, K. N., \& Lajunen, T. (2008a). The impact of four wheel driver on risky driver behaviors and road traffic accidents. Transportation Research, Intl Journal, Part F: Traffic Psychy \& Behaviour, 324-333.

Bener, A., \& Crundall, D. (2008c). Effects of driver behaviour on accident involvement: The role of gender and driver behaviour in Road Traffic Crashes. Int J Crashworthiness, 13(3), 331-336.

Bener, A., Humoud, S. M., Azhar, A., Price, P., Khalid, M. K., Rysavy, M., \& Crundall, D. (2007). The effect of seatbelt legislation on Hospital admissions with road traffic injuries in oil-rich fast developing country. International Journal of Injury Control and Safety Promotion, 14 (2), 103107.

Bener, A., Lajunen, T., Ozkan, T., \& Haigney, D. (2006). The effect of mobile phone use on driving style and driving skills. Int J Crashworthiness, 11, 459-465.

Bener, A., Ozkan, T., \& Lajunen, T. (2008b). The driver behaviour questionnaire in Arab Gulf Countries: Qatar and United Arab Emirates. Accid Anal \& Prev, 40, 1411-1417.

Bener, A. (2009a). Emerging trend in motorization and the epidemic of road traffic crashes in an economically growing country. International Journal of Crashworthiness, 14(2), 183-188. 
Finch, D. J., Kompfner, P. Lockwood, C. R., Maycock, G. (1994). Speed, speed limits and accidents (Project Report 58). Crowthorne, Transport Research Laboratory.

Gururaj, G. (2002). Epidemiology of traumatic brain injuries: Indian Scenario. Neurol Res, 24, 24-28.

Hirst, W. M., Mountain, L. J., \& Maher, M. J. (2005) Are speed enforcement cameras more effective than other speed management measures? An evaluation of the relationship between speed and accident reductions. Accid Anal Prev, 31, 731-741.

Jacob, G., Aeron-Thomas, A., \& Astrop, A. (2000). Estimating the global road fatalities, TRL report No.445.

Jha, N., Srinivasa, D. K., Roy, G., \& Jagadish, S. (2003). Injury pattern among road traffic accident cases: A study from South India. Indian J Community Med, 28, 85-90.

Krug, E. G. (2004). Injury surveillance is key to preventing injuries. Lancet, 364, 1563-1566.

Ministry of Public Health Malaysia. (1997). Epidemiology of injury in Malaysia, Injury Prevention and Control Unit, Disease Control Division, Public Health Department, Ministry of Health Malaysia.

Nantulya, V., \& Reich, M. (2003). Equity dimensions of road traffic injuries in low and middle income countries. Inj Control Saf Promot, 10, 13-20.

Patil, S. S., Kakade, R. V., Durgawale, P. M., \& Kakade, S. V. (2008). Pattern of road traffic injuries: A study from Western Maharashtra. India J Community Med, 33, 56-57.

Paulozzi, L. J., Rayan, G. W., Espitia-Hardeman, V. E. \& Xi, Y. (2007). Economic developments effect on road transport related mortality among different types of road users: a cross-sectional international study. Accid Anal Prev, 30, 606-617 .

Peden, M. (2005). Global collaboration on road traffic injuries prevention, Int J Inj Cotr Saf Promot, 12, 85-91.

Peden, M., McGee, K., \& Sharma, G. (2002). The injury chart book: a graphical overview of the global burden of injuries, Geneva. World Health organization.

Peden, M., Scurfield, R., Sleet, D., Mohan, D., Hyder, A. A., Jarawan, E., \& Mathers, C. (2004). World report on road traffic injury prevention. Geneva. World Health Organization.

Sabbagh Ebrlich, S., Friedman, I., \& Richter, E. (2005). Working conditions and fatigue in professional drivers at Israeli ports, Inj Prev, 11, 110-14.

Twisk, D. A., \& Stacey, C. (2007). Trends in young driver risk and countermeasures in European Countries, J Safety Res, 38, 245-57.

Wong, S. C., Sze, N. N., Lo, H. K., Hung, W. T., \& Loo, B. P. Y. (2005). Would relaxing speed limits aggravate safety? A case study of Hong Kong. Accid, Anal \& Prev, 37, 377-388.

World Health Organization. (2004). World Report on road traffic injury prevention, WHO, Geneva. 
A. Bener, H. R. Burgut ,H. Sidahmed, R. AlBuz, R. Sanya, W. A. Khan / Californian Journal of Health Promotion 2009, Volume 7,

Author Information

Prof. Abdulbari Bener*

Advisor to World health Organization

Consultant and Head

Dept. of Medical Statistics \& Epidemiology

Hamad General Hospital,

Hamad Medical Corporation, and

Weill Cornell Medical College

PO Box 3050

Doha - STATE OF QATAR

Tel: +974- 4393765

Tel: +974- 4393766

Fax:+ 974- 4393769

e-mail: abener@hmc.org.qa

e-mail:abb2007@qatar-med.cornell.edu

Huseyin R. Burgut

Depts. of Public Health \& Medical Education, Weill Cornell Medical College, Qatar

Heba Sidahmed

Depts. of Public Health \& Medical Education, Weill Cornell Medical College, Qatar

Rama AlBuz

Depts. of Public Health \& Medical Education, Weill Cornell Medical College, Qatar

Rahima Sanya

Depts. of Public Health \& Medical Education, Weill Cornell Medical College, Qatar

Waleed Ali Khan

Depts. of Public Health \& Medical Education, Weill Cornell Medical College, Qatar

* corresponding author 